\title{
Carbon dioxide measurements using long period grating optical fibre sensor coated with metal organic framework HKUST-1
}

\author{
Jiri Hromadka ${ }^{1,2}$, Begum Tokay $^{3}$, Ricardo Correia ${ }^{1}$, Stephen P Morgan ${ }^{1}$ and Sergiy Korposh ${ }^{l}$ \\ ${ }^{1}$ Optics and Photonics Group, Faculty of Engineering, University of Nottingham, University Park, \\ Nottingham NG7 2RD, United Kingdom \\ ${ }^{2}$ Institute for Environmental Studies, Faculty of Sciences, Charles University in Prague, \\ Benátská 2, CZ 12843 Praha 2, Czech Republic \\ ${ }^{3}$ Chemical and Environmental Engineering Department, Faculty of Engineering, University of \\ Nottingham, University Park, Nottingham NG7 2RD, United Kingdom
}

\begin{abstract}
An optical fibre long period grating (LPG) based carbon dioxide $\left(\mathrm{CO}_{2}\right)$ sensor coated with HKUST-1, a material from the metal organic framework family, functional coating is presented. In-situ crystallization and layer by layer (LbL) techniques of HKUST-1 thin film synthesis are compared in terms of the feasibility of the deposition procedure (time and cost efficiency) and the sensitivity of the film to carbon dioxide. The sensing mechanism is based on the measurement of the change of the refractive index (RI) of the coating that is induced by the penetration of $\mathrm{CO}_{2}$ molecules into the HKUST-1 pores. The HKUST-1 film was characterized by scanning electron microscopy (SEM). The thickness and refractive index (RI) of the 10 , 20 and 40 layers thick films were determined using ellipsoetry. The crystallinity of the films was examined by X-ray diffraction pattern (XRD). While no response to $\mathrm{CO}_{2}$ was observed for the sensor coated using the in-situ crystallization technique, an LPG modified with 10, 20 and 40 layers of HKUST-1 films using LbL method upon exposure to $\mathrm{CO}_{2}$ in the range of $500 \mathrm{ppm}$ to $40,000 \mathrm{ppm}$ showed good sensitivity. The film containing 40 layers exhibited the highest sensitivity to $\mathrm{CO}_{2}$ with an obtained detection limit of $401 \mathrm{ppm}$.
\end{abstract}

Keywords: Long period grating (LPG), metal organic framework (MOF), HKUST-1, layer by layer deposition, carbon dioxide $\left(\mathrm{CO}_{2}\right)$ sensor 


\section{Introduction}

Carbon dioxide $\left(\mathrm{CO}_{2}\right)$ is the product of the metabolism of organisms and it is naturally present in the atmosphere in levels between 350-400 ppm, with higher concentrations in urban areas. The levels of $\mathrm{CO}_{2}$ are of scientific and public concern because of the global warming impact and climate change (1). The detection of $\left(\mathrm{CO}_{2}\right)$ is necessary and important in a wide range of applications including indoor air quality (2), food industry (3) and healthcare (4). The monitoring of dissolved $\mathrm{CO}_{2}$ (and related inorganic carbon) e.g. in seawater is of high interest and represents another area where the new sensor for real-time and remote measurement is desired (5).

According to the workplace regulations, the concentration of $\mathrm{CO}_{2}$ in the workspace should be kept below $5,000 \mathrm{ppm}$ as the 8 hour average (6). However, even lower concentrations can cause discomfort, headache or tiredness to sensitive individuals (7). Relatively high concentrations of $\mathrm{CO}_{2}$ have been linked, for example, to a decrease in performance of children at school (7). The $\mathrm{CO}_{2}$ concentration is also related to other pollutants and it could be used as the indicator of fresh air (8), e.g. it could be used for indoor air climate control using the ventilating units (9) or help ventilating units to operate in the most efficient way and thus increase the energy performance of buildings (10).

The measurement of $\mathrm{CO}_{2}$ in the food industry is important for the monitoring of i) the atmosphere during food packaging, where the $\mathrm{CO}_{2}$ decrease indicates a leak in the package (11), ii) the ventilation control in potato storage facilities (12) or iii) stored grains in farm granaries to detect any spoilage (13).

The measurement of $\mathrm{CO}_{2}$ is highly desired in the field of medical care, where the portion of $\mathrm{CO}_{2}$ in exhaled gas (referred as end-tidal $\mathrm{CO}_{2}$ ) is used to diagnose hypermetabolic conditions such as sepsis (14) or malignant hyperthermia (15). A newly developed $\mathrm{CO}_{2}$ sensor for medical applications ideally should satisfy the following criteria: i) fast response time, ii) minimize the dead space of the tracheal tube and the device itself, ideally to provide the measurement inside the endotracheal tube and iii) should not be affected by a rapid respiration rate (4).

Non-dispersive infra-red (NDIR) sensors represent the currently most used technique for the detection of $\mathrm{CO}_{2}$ however their use is limited by the high cost typically in the range of several hundred pounds. The performance of the sensor could also be affected by other gases or by the high concentration of water vapour (3). Gas chromatography coupled with Mass spectroscopy (GC-MS) can be used for the detection of $\mathrm{CO}_{2}$ whilst this approach is more expensive than NDIR sensors and cannot be used for real-time measurements (3).

Fibre-optic sensing platforms are small, lightweight, immune to electromagnetic interference and as such 
can be used in extreme conditions, enabling remote real time monitoring with no electrical power needed at the sensing point (16). Among the different types of fibre-optic sensors, those based on gratings, specifically long period gratings (LPGs), have been employed extensively for refractive index measurements (17) and for monitoring associated chemical processes (17), since they offer wavelengthencoded information, which overcomes the referencing issues associated with intensity based approaches. An LPG consists of a periodic perturbation of the refractive index of the fibre core, which couples the core mode to the co-propagating cladding modes of the fibre. This coupling is manifested in the transmission spectrum of the optical fibre as a series of resonance bands. Each resonance band corresponds to coupling to a different cladding mode and thus shows different sensitivity to environmental changes (18).

The coupling wavelength can be obtained from the following phase matching equation

$$
\lambda_{\mathrm{x}}=\left(\mathrm{n}_{\mathrm{core}}-\mathrm{n}_{\mathrm{clad}(\mathrm{x})}\right) \Lambda
$$

Where $\lambda_{x}$ represents the wavelength at which light is coupled to the $\mathrm{LP}_{0 \mathrm{x}}$ cladding mode, $n_{\text {core }}$ is the effective refractive index of the mode propagating in the core of the fibre, $n_{\operatorname{clad}(x)}$ is the effective index of the $\mathrm{LP}_{0 \mathrm{x}}$ cladding mode and $\Lambda$ is the period of the LPG (18). The central wavelength of the resonance band is sensitive to changes in the surrounding environment such as temperature or external index of refraction (18). $\mathrm{LP}_{0 \mathrm{x}}$ cladding modes represent the approximation of the behaviour of the light propagating through the fibre however still provide enough accuracy to be used for the calculation and modelling of LPG properties (19)

Various methods have been employed for the deposition of the functional film onto the optical fibre to endow it with chemical sensitivity (20)(21)(22)(23). Fibre-optic sensing platforms based on LPGs modified with appropriate functional coatings have been used to measure/determine various measurands including relative humidity (24)(22)(25), ammonia (20)(26) and volatile organic compounds (VOCs) (27)(28). In addition, when proteins, enzymes or antibodies are incorporated, then optical fibres can be used for biological response measurement (29)(30)(31)(32). Among the various techniques used for the deposition of the sensitive element, layer-by-layer (LbL) assembly is considered highly versatile, enabling control over the structure of the deposited material. This technique can be used to deposit a wide range of materials onto a range of substrates and represents a cheap, simple and rapid approach for thin film deposition (33).

As the LPG is sensitive to temperature, the implementation of the LPG based chemical sensor into an LPG array represents the most effective option for subtraction of any environmental temperature changes and thus enable the use of the sensor in the real environment (34).

Metal organic frameworks (MOFs), can be considered as crystalline materials with tuneable porosity, 
large internal surface area and organic functionality. The strong metal-oxygen-carbon bonds imbue the materials with high chemical and thermal stabilities (35). There have been limited reports of MOF based sensors, but they indicate their potential to become powerful analytical devices (36).

The applications of MOFs have been reviewed elsewhere (37)(38)(39), where main applications were identified in selective hydrogen gas storage (40), selective gas adsorption and separation (41), or catalysis (42). It has been shown that MOFs offer an ideal platform for the development of sensitive films with responses to specific analytes (36)(43)(44). The ability to adjust the pore size and to perform post-synthesis functionalization enables the development of MOFs that offer specific reactions with an analyte of interest, where only certain molecules (treated by size or functional group) are allowed to enter into the MOF's cavities however the problem with signal transduction represents the key issue for the MOF based sensors (44).

The uniformity of the film in terms of its structure, thickness and crystal orientation is desired, because these parameters influence drastically the performance of the sensor. The choice of the deposition technique plays an important role in MOF thin film fabrication as it can affect all of these crucial parameters (43).

We have recently demonstrated that a fibre optic LPG offers an ideal platform for the deposition of the MOF film as the sensitive element to fabricate a chemical sensor with high selectivity and sensitivity. Due to the properties of the LPG, the change in the refractive index of the whole film induced by the presence of the analyte can be observed in the transmission spectrum (28). Among the variety of MOFs, thin film of HKUST-1 is considered to be highly selective for $\mathrm{CO}_{2}$ sensing due to the presence of unsaturated copper ${ }^{\text {(II) }}$ metal centres and its structure, which consists of two large central cavities (9 ^) surrounded by smaller 5 $\AA$ cavities (45).

The structure of HKUST-1 film is schematically shown in Figure 1Figure 1. 


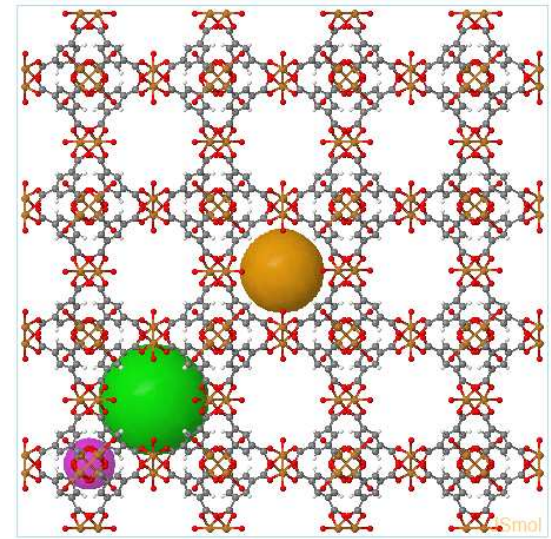

Figure 1: HKUST-1 3D structure (The sphere represents the pore size within the framework which can be used for gas storage) (46).

In this work, for the first time to the best of authors' knowledge, the optical fibre based HKUST-1 carbon dioxide sensor was investigated. HKUST-1 thin film was deposited onto the surface of an optical fibre LPG as the sensing platform. Within the various MOF thin film fabrication techniques, there are two approaches highly suitable for the deposition of the sensitive film on the surface of LPG: i) in situ crystallization technique and ii) LbL technique. Both are compared in terms of the feasibility of the deposition procedure (time and cost efficiency) and the sensitivity of the film to $\mathrm{CO}_{2}$. In situ crystallization represents the simplest technique for the fabrication of MOF films whilst the fabrication time can differ from hours to days (43). Rapid thermal deposition can significantly decrease the crystallization time due to the rapid solvent evaporation at elevated temperature, but still enables the synthesis of well inter-grown MOF film (47).

Layer by layer (LbL) deposition has been used previously for the fabrication of MOF films (48)(49) and its use is desired due to the simplicity of the procedure, which is conducted at room temperature and requires shorter time in comparison to other techniques. In particular, the LbL approach for HKUST-1 leads to the fabrication of films with higher crystal density, conforming into homogenous films with preferred $\{222\}$ orientation (49).

This work compares the properties of the HKUST-1 films prepared by two different approaches, characterised using the different techniques and investigates the sensitivity to $\mathrm{CO}_{2}$ of the novel fibre optic sensor. 


\section{Methodology}

\subsection{Materials}

Copper nitrate hemi(pentahydrate) $\left(\left[\mathrm{Cu}\left(\mathrm{NO}_{3}\right) 2 \cdot 2.5 \mathrm{H}_{2} \mathrm{O}\right]\right), 1,3,5$-benzene tricarboxylic acid (BTC), dimethylformamide (DMF), copper acetate $\left(\mathrm{Cu}\left(\mathrm{CH}_{3} \mathrm{COO}\right)_{2}\right)$, potassium hydroxide $(\mathrm{KOH})$ and ethanol were bought from Sigma Aldrich. All of the chemicals were analytical grade reagents and used without further purification. Deionized water $(18.3 \mathrm{M} \Omega \mathrm{cm})$ was obtained by reverse osmosis followed by ion exchange and filtration (Millipore, Direct-QTM).

\subsection{Characterization of HKUST-1 films}

Scanning electron microscopy, X-Ray diffraction and ellipsometry measurements were conducted to evaluate the properties of the HKUST-1 thin films. The procedures followed the ones described in (28). The properties of the film deposited either on glass slides and the surface of an optical fibre LPG has been previously reported to be similar (Korposh et al., 2012) thus the properties of the film have been evaluated on the glass substrates.

Briefly, scanning electrone microscope (SEM) was used to evaluate the structure and thickness of the films deposited on glass substrates. Glass slides of dimensions $1 \times 1 \mathrm{~cm}^{2}$ and $2 \times 2 \mathrm{~cm}^{2}$ were cut from standard microscope glass slides and then coated with HKUST-1 thin films, following the procedure described in sections 2.4 and 2.5 .

The thicknesses of the films on the glass substrates were further evaluated using an ellipsometer. The measurements were undertaken using an Alpha-SE Ellipsometer (J.A Woolan) and the data processed using a model assuming a transparent film on a glass substrate. Data were collected at a spectral resolution of 1 $\mathrm{nm}$ and measured in the wavelength range of $380-900 \mathrm{~nm}$; for simplicity the RI value of the mesoporous film was determined at one wavelength $(632.8 \mathrm{~nm})$.

$X$-ray diffraction patterns were collected using a Bruker-AXS D8 Advance diffractometer, using $\theta / \theta$ goniometer geometry, a Cu-anode line-focus x-ray tube (powered at $40 \mathrm{kV} \& 35 \mathrm{~mA}$ ), a Göbel mirror (producing a parallel $\mathrm{CuK} \alpha$ beam) with a $0.6 \mathrm{~mm}$ exit slit, a diffracted beam $0.12^{\circ}$ Soller-slit collimator and a scintillation counter $x$-ray detector. The samples were scanned with a fixed glancing incident angle of 2.140 and $1.140^{\circ}$, over a $2 \theta$ range of $5^{\circ}$ to $40^{\circ}$, with a $2 \theta$ step size of $0.02^{\circ}$ and a step time of $32 \mathrm{~s}$.

\subsection{Sensor fabrication and functionalization}

Two different methods were used to inscribe LPGs with different period in the core of the optical fibre. LPGs with grating periods of 109.2 and $108.8 \mu \mathrm{m}$ and length of $30 \mathrm{~mm}$ were fabricated using point-by- 
point approach. These gratings were functionalized using in situ crystallization and the LbL technique respectively.

A single LPG with period of $109.0 \mu \mathrm{m}$ and an-An LPG array consisting of LPGs with periods of 109.5 and $110.5 \mu \mathrm{m}$ and each of length of $30 \mathrm{~mm}$ wasere fabricated using an amplitude mask and UV laser illumination and further functionalized using only the LbL technique. Both LPGs are sensitive to the temperature, while only LPG1 is sensitive to $\mathrm{CO}_{2}$ (after the deposition of HKUST-1) and so any changes in the difference of the position of the central wavelengths corresponding to the bare and the coated LPGs are due to response to $\mathrm{CO}_{2}$ only. The LPG array is schematically shown in Figure 2Figure 2. Three other sensors consisting of one single LPG with period of $109.0 \mu \mathrm{m}$ have been fabricated using amplitude mask and UV laser illumination and coated using LbL technique (10, 20 and 40 layers). Those sensors operate at PMTP and thus at the highest sensitivity.

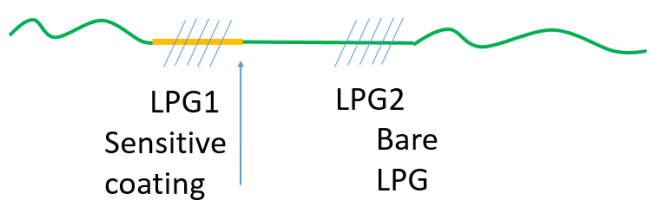

Figure 2: Scheme of the proposed $L P G$ based $\mathrm{CO}_{2}$ sensor

All the fabrication and deposition procedures followed the methodology described in (50) for a point by point approach and in (51) for the fabrication via amplitude masks. Although two different fabrication methods were used to coat the LPGs, we have observed that this does not affect the performance of the bare sensors and any differences in the response are due to the properties of the functional coating. The surface of LPG was functionalized with $\mathrm{OH}^{-}$groups prior to the fabrication of the HKUST-1 film. The optical fibre was rinsed with deionized water and immersed in a $1 \mathrm{wt} \% \mathrm{KOH}$ in ethanol/water $=3: 2 \mathrm{v} / \mathrm{v}$ solution for 20 $\min$.

The use of the grating period in the region of $110 \mu \mathrm{m}$ ensures that the LPG will operate at PMTP, and thus operate with highest sensitivity. Even more, both resonance bands at PMTP lie towards the red end of the visible spectrum, allowing the transmission spectrum of the LPG to be monitored using an inexpensive light source, halogen lamp, and a low-cost CCD spectrometer. 


\subsection{In-situ crystallization technique}

The LPG was coated with HKUST-1 via in-situ crystallization technique using rapid thermal deposition (47), Figure 3.

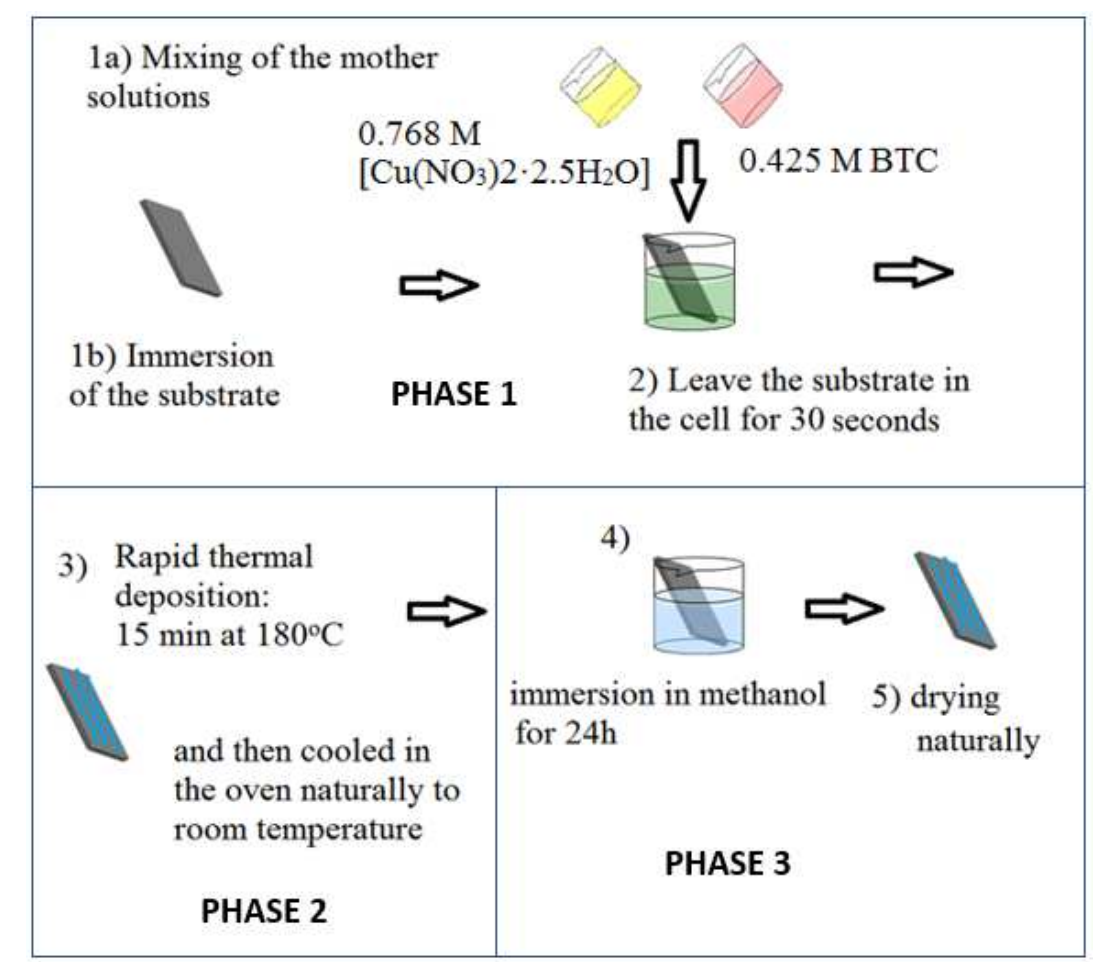

Figure 3: Schematic illustration of the HKUST-1 film fabrication methodology using in-situ crystallization technique (47).

The mother solutions of $0.768 \mathrm{M}$ copper nitrate hemi(pentahydrate) (metal solution) and $0.425 \mathrm{M}$ BTC (ligand solution) in DMF has been prepared and stirred for $10 \mathrm{~min}$. The ligand solution was then added to the metal solution dropwise and the mixture was stirred until a clear solution was obtained, the volume ratio between those mother solutions was 1:1 (47). $14 \mathrm{~mL}$ of the mixed solution was injected into the Petri dish using a pipette.

The LPG was placed inside the Petri dish and immersed into the film forming solution for a period of $30 \mathrm{~s}$ and then the excess of the solution was carefully wiped with Kimwipes. The LPG was subsequently 
placed into an oven preheated to $180^{\circ} \mathrm{C}$. The oven was switched off after $15 \mathrm{~min}$ and the LPG was left to cool down naturally. When the temperature was close to the ambient level, the LPG was immersed in methanol for 24 hours to remove DMF from the HKUST-1 cavities and replace it with methanol and then left to dry under the ambient conditions (to release methanol from the cavities to make the porous structure of the film) (47).

\subsection{Layer by layer technique}

Alternatively, the LPG was coated with HKUST-1 using LbL method described in details elsewhere (49). Briefly, solutions of $1 \mathrm{mM} \mathrm{BTC}$ and $0.2 \mathrm{mM}$ copper acetate in ethanol were prepared. The optical fibre was immersed into a $\mathrm{Cu}_{2}\left(\mathrm{AcO}_{4}\right)$ solution and then into a BTC solution for 5 min each, resulting in the alternate deposition of $\mathrm{Cu}^{2+}$ and $\mathrm{BTC}^{-}$, forming an HKUST-1 film on the surface of LPG. Between each of these steps, the LPG was immersed in ethanol for $10 \mathrm{~min}$ to remove all unreacted parts of film forming solutions. The process was repeated to obtain a thicker film consisting of 10, 20 or 40 growth cycles. Transmission spectra were recorded continuously during the deposition process. The HKUST-1 LbL deposition is schematically shown in Figure 4Figure 4.

Formatted: English (United Kingdom)

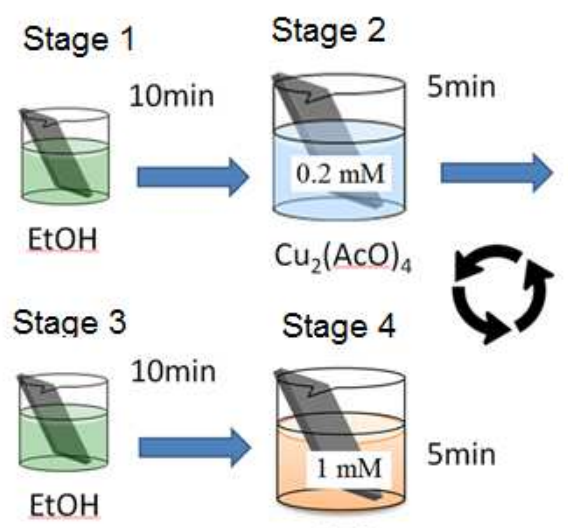

BTC

Figure 4: Schematic illustration of the HKUST-1 film fabrication methodology using layer by layer technique (49).

The effect of the immersion in pure ethanol (for $10 \mathrm{~min}$ at the beginning and then as an intermediate step between the immersions to metal and ligand solutions) on the quality of the film has been investigated. Two approaches of the LbL method were used: i) following the procedure published in (49), shown in (Figure 
4Figure 3) and ii) replacing the immersion in ethanol - phase 1 and 3 indicated in Figure 4Figure 3 - by rinsing with ethanol (conducted three times using a pipette). The crystallization process occurs during the immersion time and the formation of larger crystals are expected in the film however the size and the quality of the crystals does not represent the main target for the proposed sensing application. HKUST-1 structure plays a key role with reactive - binding sites developed. The fabrication time can be reduced rapidly in the later method using the washing by ethanol only, where the residues of unreacted parts of the initial (mother) solutions are removed from the evolving HKUST-1 film.

\subsection{Sensor performance}

The performance of the LPG as a chemical sensor was investigated by exposing the coated device to the concentration range (500-40,000 ppm) of carbon dioxide. The response of the LPG was investigated with the fibre positioned in an environmental chamber composed of a closed polytetrafluoroethylene (PTFE) box $(15 \times 15 \times 15 \mathrm{~cm})$. The LPG was fixed $5 \mathrm{~cm}$ above the base of the chamber.

The experimental set-up is schematically shown in Figure 5Figure 5.

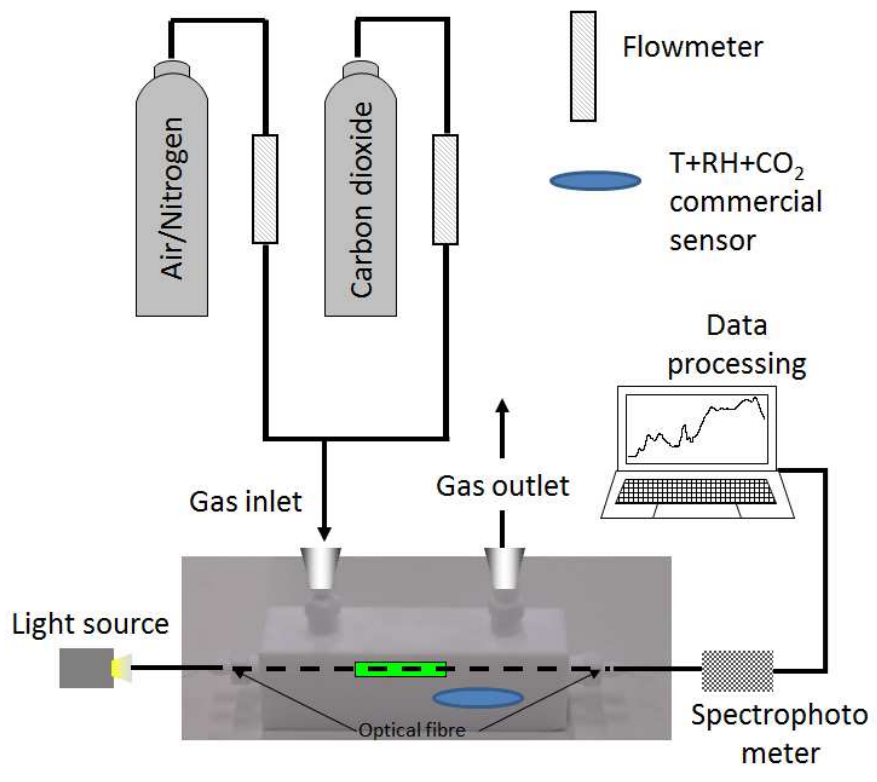

Figure 5: Schematic illustration of the experimental set-up for $\mathrm{CO}_{2}$ sensitivity experiments. The chamber is initially filled with nitrogen and then the concentration of $\mathrm{CO}_{2}$ increased. The LPG optical fibre 
sensor is placed in the chamber and the light transmitted through the fibre measured using spectrophotometer.

The chamber was initially filled with nitrogen and then the concentration of $\mathrm{CO}_{2}$ gas was increased by infusion of the mixture of $\mathrm{CO}_{2}$ and argon to increase $\mathrm{CO}_{2}$ level from $\sim 500 \mathrm{ppm}$ up to $\sim 40,000 \mathrm{ppm}$.

The central wavelengths of the resonance bands in the LPG's transmission spectra were recorded and their response to the presence of $\mathrm{CO}_{2}$ was measured. The concentration of $\mathrm{CO}_{2}$, the temperature and the relative humidity $(\mathrm{RH})$ were recorded by a data logger (K-33 ICB $30 \% \mathrm{CO}_{2}$ sensor from CO2meter, Inc.), placed inside the chamber next to the LPG. An acquisition interval of $20 \mathrm{~s}$ was set for all experiments (it represents the minimal interval of a commercial data logger).

\section{Results and discussion}

\subsection{Film morphology and thickness}

The SEM images allow the assessment of the coverage of the glass-slide substrate and of the uniformity of the thickness of the deposited HKUST-1 film. Three different approaches of the deposition techniques were examined; deposition: i) via in-situ crystallization technique; ii) layer by layer with $10 \mathrm{~min}$ crystallization in ethanol and iii) layer by layer with ethanol rinsing.

A homogenous crystalline film, uniformly covering the substrate was observed for all methods (i)-(iii); in-situ crystallization technique (Figure S1) and LbL approach following the procedure with immersion to ethanol (Figure 6Figure 6). The single crystals can be recognized for methods (i) and (ii) however the much smaller crystals were identified for the LbL procedure with ethanol rinsing, method (iii), Figure 7Figure 7. 


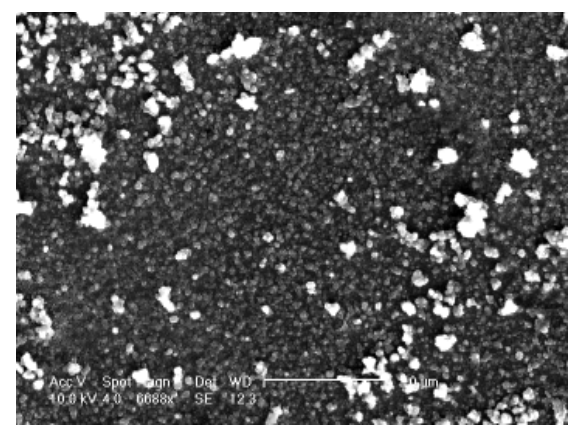

(a)

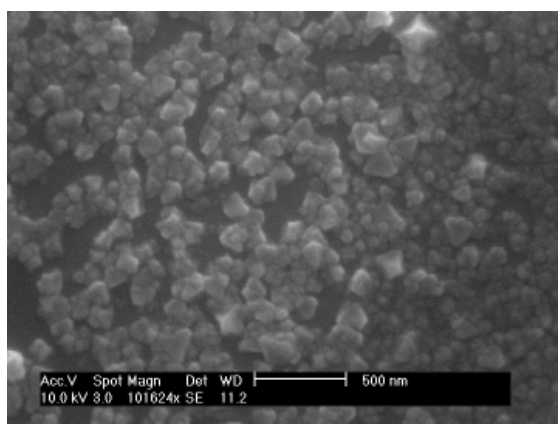

(b)

Figure 6: SEM images of the morphology of 40 layers of HKUST-1 film grown on a glass substrate via the LbL technique following the ethanol immersion step, method (ii) a) scale bar $=20 \mu \mathrm{m}$ and $b$ ) scale bar $=500 \mathrm{~nm}$

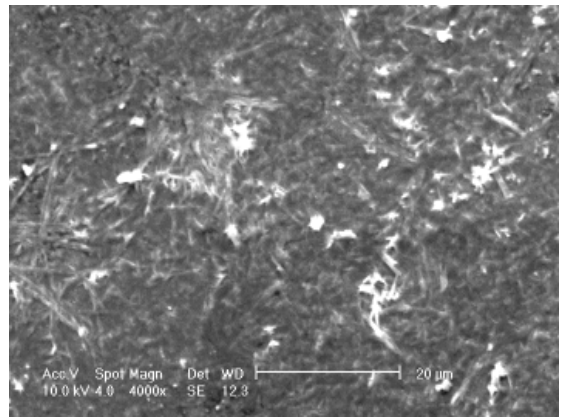

(a)

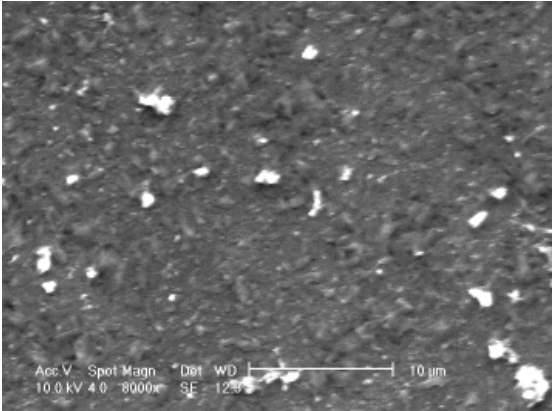

(b)

Figure 7: SEM images of the morphology of 40 layers of HKUST-1 film grown on glass substrate via the LbL technique with use of ethanol washing, method (iii) (a) scale bar $=20 \mu \mathrm{m}(\mathrm{b})$ scale bar $=10 \mu \mathrm{m}$

This finding supports the hypothesis that 10 min of immersion in ethanol plays a similar role for the HKUST-1 crystallization as the Phase 2, rapid thermal development, for the in-situ crystallization technique (47). Although individual crystals could not be detected, the deposited HKUST-1 film had a structure that was different compared to the precursors suggesting the sufficient growth of HKUST-1 crystals.

This observation is in a good agreement with the previously reported study characterizing the HKUST1 film deposited onto the quartz microbalance substrate using the LbL approach. No changes in mass 
frequency during the deposition when the substrates were immersed in ethanol was observed (49).

The immersion step in ethanol affected the size and quality of the crystals and reduced the deposition time (from $30 \mathrm{~min}$ to $10 \mathrm{~min}$ per layer). Consequently, the modified deposition procedure (iii) was used instead of the LbL deposition, method (ii) onto the surface of LPGs.

The film thickness obtained via the in-situ crystallization technique was estimated to be $2 \mu \mathrm{m}$ based on the cross-sectional SEM image, Figure S1c. On the other hand, the thickness of the film fabricated via LbL technique was expected to be in a range of $10 \mathrm{~s}$ of $\mathrm{nm}(49)$ and for this reason the thickness measurements were conducted using the ellipsometer, where the results indicated the film thickness of $\approx 55,20$ and $10 \mathrm{~nm}$ for 40, 20 and 10 layered film. No significant difference in film thickness was observed between different LbL procedures (ii) and (iii), containing the step with and without the immersion into ethanol, respectively.

\subsection{Film structure}

X-ray diffraction patterns establish that the films comprised HKUST-1 crystals. The positions of the peaks $\{200\},\{220\},\{311\},\{222\},\{400\},\{331\},\{420\},\{333\}$ and $\{440\}$ indicate a crystalline HKUST1 structure, Figure 8 Figure 8 . The highest intensity, at the $\{222\}$ reflection peak, suggests that the orientation of the crystals is preferred to be out of plane orientation along the $\{222\}$ crystallographic direction. The elevated plateau from 15 to $402 \theta^{\circ}$ relates to the amorphous structure of the glass substrate. The position and the intensity of the peaks in Figure 8:Figure 8 are in a good agreement with the X-ray diffraction patterns reported in the literature and also with the modelled diffraction pattern for HKUST-1 (47).

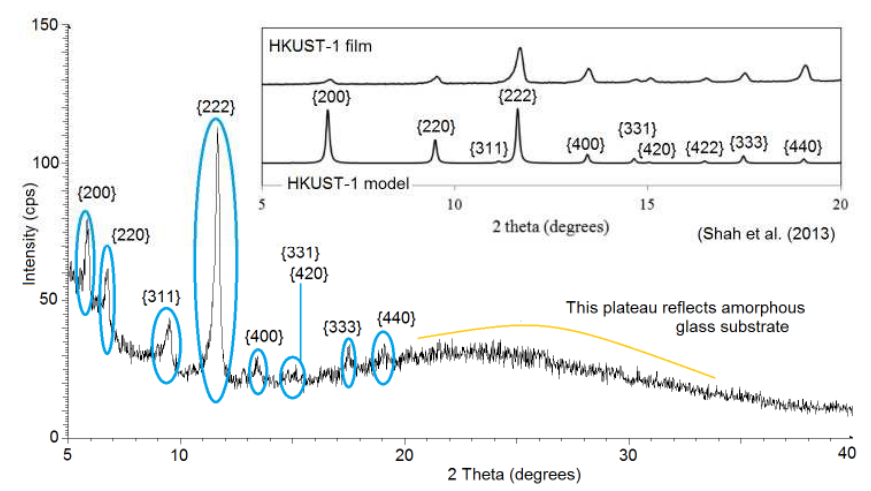

Figure 8: In-plane X-Ray diffraction patterns of HKUST-1 film on glass substrate, recorded at room temperature; inset on the right top shows the results obtained in (47) and modelled values. 


\subsection{LPG modification using in-situ crystallization technique}

The evolution of the transmission spectrum of the LPG with period of $110.0 \mu \mathrm{m}$ during the HKUST-1 deposition process is shown in Figure S2. After the immersion of LPG into the mother solution (Phase 1) the change of $33.35 \mathrm{~nm}$ in the central wavelengths difference operating at the phase matching turning point (PMTP) and of $32.15 \%$ in the transmission loss (for LPG-R) was observed. The attenuation bands operating at the PMTP have almost disappeared, Figure S2a (red line). This effect could be explained by the high concentration and high refractive index of the solution resulting in a big change in the transmission spectrum. The fibre was not dried, only the excess of the solution was removed, some of the liquid remained on the surface due to the adhesive forces. The residues of the mother solution caused the broadening of the attenuation band, S2b (red).

The evaporation of the solvent took place in the oven during Phase 2, associated with the increase of the transmission loss that can be observed for attenuation bands operating at the PMTP in Figure S2a (green) and for $\mathrm{LP}_{018}$ cladding mode in Figure S2b (green). Rapid thermal deposition induced crystallization of the HKUST-1 structure, where DMF was still filled in the cavities. This structural change can explain the further shift (separation) of the central wavelengths operating at the PMTP and LP ${ }_{018}$ cladding mode.

DMF was replaced in the cavities by methanol that was subsequently left to evaporate. The further shift of the central wavelengths and decrease in transmission loss was observed, where LPG-R disappeared and LPG-L showed a very weak transmission loss, Figure S2Error! Reference source not found.a (blue). The same trend was observed over the change of central wavelength corresponding to $\mathrm{LP}_{018}$ cladding mode, Figure S2b (blue).

Changes in the transmission spectra central wavelength $(\mathrm{ca} .670 \mathrm{~nm}$ ) corresponding to LP018 cladding mode were monitored during the whole Phase 1 and Phase 3 -were monitored via the change of the central wavelength corresponding to $\mathrm{LP}_{018}$-cladding mode, Figure S3a and S3b, respectively. After immersion of the LPG into film forming solution there is a blue shift of the central wavelength from 672 to $662 \mathrm{~nm}$ followed by The evolution of the transmission spectrum while the LPG was in the film forming solution showed a continuous red shift of the central wavelength in the first $30 \mathrm{~s}$ after the immersion followed by saturation, inset of Figure S3a. After LPG was withdrawn from the solution there is a ca $2 \mathrm{~nm}$ blue shift in the central wavelength as compared with the bare LPG implying deposition of the MOFs thin film on the LPG fibre, Figure S3a. Further blue shift is observed after methanol treatment, Figure S3b.

A minimal shift of the central wavelength was observed within the first $10 \mathrm{~h}$ while the LPG was immersed in methanol during the Phase 3 followed by the continuous change that saturated approximately after 20 h, Figure S3b. These changes are expected to be associated with the replacement of DMF by 
methanol in HKUST-1 cavities.

\section{$3.4 \mathrm{CO}_{2}$ sensing using in-situ crystallization technique}

When exposed to $\mathrm{CO}_{2}$, no measurable change of the central wavelength was observed, as the response to the high concentration of $\mathrm{CO}_{2}$ in the range from $\sim 500$ to $\sim 5,500 \mathrm{ppm}$, Figure $\mathrm{S} 4$. The continuous shift in the position of the central wavelength matches the continuous shift in the temperature, where no steps according to the levels of $\mathrm{CO}_{2}$ were observed.

This observation could be explained due to the influence of the ambient humidity present in air. While the sensitivity of HKUST-1 to $\mathrm{CO}_{2}$ was demonstrated previously as the gas partial pressure in vacuum (49), it is known that water vapour can react with the open copper sites in the HKUST-1 structure and then block their specific affinity to $\mathrm{CO}_{2}$ molecules. HKUST-1 structure can collapse as a result of water adsorption. This effect was previously described for degradation with time of a HKUST-1 film stored under elevated relative humidity levels (49).

To further test this hypothesis, another LPG with period of $109.5 \mu \mathrm{m}$ was coated by HKUST-1 film using the in-situ crystallization technique and exposed to the mixture of nitrogen and $\mathrm{CO}_{2}$ up to the $\mathrm{CO}_{2}$ concentration of $\sim 42,000 \mathrm{ppm}$. The transmission spectra before and after the deposition of HKUST-1 are shown in Figure S5.

When the LPG was exposed to $\mathrm{CO}_{2}$ the position of the central wavelength responded again to temperature only and no observable shift was measured as the response to $\mathrm{CO}_{2}$, Figure S6. The drop of the central wavelength at $100 \mathrm{~min}$ was probably caused by the relaxation of the fibre due to the nitrogen flow (the intensity of the whole transmission spectrum reduced at this time).

No response of the sensor to $\mathrm{CO}_{2}$ could also be explained by the high film thickness, estimated to be $\approx$ $2 \mu \mathrm{m}$ (Figure S1c), which greatly exceeded the optimum region for the sensitive coating in a range of hundreds of nm (52).

The HKUST-1 film is affected by water vapour (humidity), where the crystals change their structure irreversibly, when they are in contact with water molecules and the film is no longer sensitive to carbon dioxide and for this reason the sensor was tested under the nitrogen atmosphere. This issue can be obeyed by the deposition of the thin film over the HKUST-1, that will be permeable for gases but not for water, as an example the protection coating can be made from Teflon (53) or polydimetyl siloxane (PDMS) (54).

The experiments with the LPG sensors modified by LbL technique were undertaken using mixtures of nitrogen and $\mathrm{CO}_{2}$ to investigate further the sensitivity of deposited HKUST-1 films to $\mathrm{CO}_{2}$. 


\subsection{LPG modification using layer by layer technique}

The all measurements were done following the method (iii), described in the section 3.1. An array containing LPG1 and LPG2 with periods of 109.5 and $110.5 \mu \mathrm{m}$ respectively was fabricated and LPG1 was further coated with 40 layers of HKUST-1, further referred as Array A. The performance of the array as a $\mathrm{CO}_{2}$ sensor was evaluated via changes in the central wavelength difference associated with the attenuation bands of bare and coated LPGs. The bare LPG works as a reference to subtract the effect of temperature and any other perturbation from the surrounding environment (e.g. the flow effect of the gas that could possibly cause the relaxation of the LPG). The transmission spectrum of the array taken in air before and after the deposition of HKUST-1 on LPG1 is shown in Figure 9Figure 9.

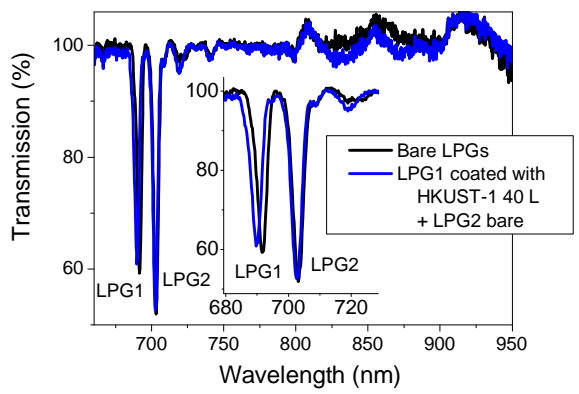

Figure 9: Transmission spectrum of Array A before (black) and after the deposition of 40 layers of HKUST-1 onto LPG1 (blue), inset show the attenuation band of LPG1 in detail.

The shift of the attenuation band corresponding to LPG1 induced by the deposition of HKUST-1 film can be observed, while the attenuation band corresponding to the bare LPG2 remained in the same position, Figure 9Figure 9.

Changes in the transmission spectrum of the LPG when immersed into the film forming solutions (metal and ligand) were monitored. The total change of the central wavelength of LPG1 associated with attenuation band corresponding to $\mathrm{LP}_{018}$ cladding mode induced by the deposition of 40 layers of HKUST-1 was measured to be 5.5 and $6.7 \mathrm{~nm}$ in air and solution respectively, Figure 10Figure 10.

The black lines, which are a guide to an eye, indicate the central wavelengths of the resonance bands show a higher sensitivity to coating thickness when the LPGs are immersed in the growth solution than they do when the LPG is in air. The "spikes" in the figure represent the short period of time during which 
the LPG was in air when the metal solution was replaced by ligand solution, Figure 10Figure 10.

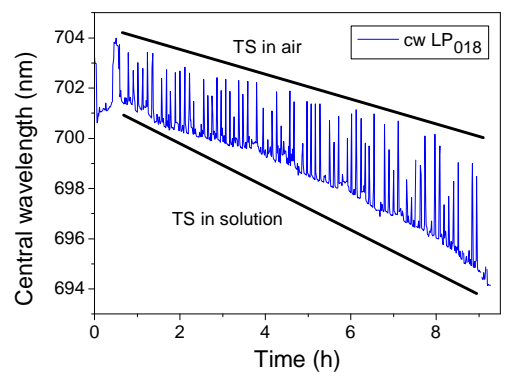

Figure 10: The dynamic shift of the central wavelength of LPG 1, Array A, corresponding to the LP018 cladding mode during the deposition of $1^{\text {st }}$ to $40^{\text {th }}$ layer of HKUST-1 onto a surface of LPG.

\section{6 $\mathrm{CO}_{2}$ sensing using layer by layer technique}

The changes in the transmission spectrum of Array A as the response to $\mathrm{CO}_{2}$ levels in a range of 2,000 $40,000 \mathrm{ppm}$ are shown in Figure 11Figure 11. The highest concentration of 40,000 ppm caused a $0.76 \pm 0.03$ $\mathrm{nm}$ change in the position of the central wavelength of the coated LPG (Figure 11Figure 11b) corresponding to $\mathrm{LP}_{018}$ cladding mode and a higher change can be expected when the sensor is operated at the PMTP. The bare LPG2 stayed in the same position (Figure S7). The sensitivity to changes in ambient temperature was minimal in this case as the sensor isn't operating at the PMTP.

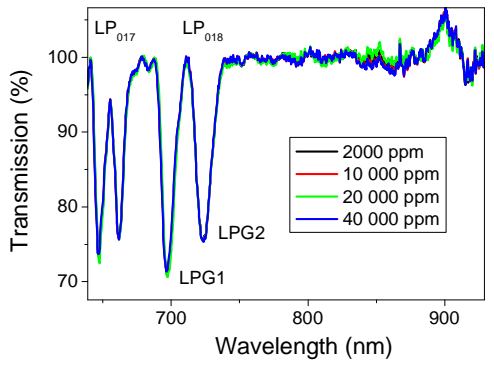

(a)

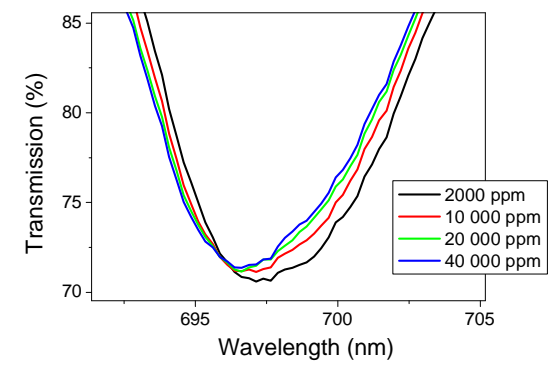

(b) 
Figure 11: Transmission spectrum of a) LPG 1 coated with 40 layers of HKUST-1 at exposure to 2,000 (black), 10,000 (red), 20,000 (green) and 40,000 (blue) ppm of $\mathrm{CO}_{2}$ and b) attenuation band of LPG1 in detail.

The sensor's performance can be tracked via the shift of the central wavelengths difference corresponding to $\mathrm{LP}_{018}$ cladding mode of LPG1 and LPG2 respectively $\left(\triangle \mathrm{CW}_{\mathrm{LP} 018}\right)$. No visible change of the bare LPG2 was observed, Figure S7. The dynamic shift of $\Delta \mathrm{CW}_{\mathrm{LP018}}$ was tracked during the $\mathrm{CO}_{2}$ sensitivity experiment (Error! Reference source not found.Figure 12).

As an example, Array A responded even to the lowest concentration of $10,000 \mathrm{ppm}$ of $\mathrm{CO}_{2}$ inducing the shift of the central wavelength difference of $0.36 \pm 0.04 \mathrm{~nm}$, Error! Reference source not found.Figure 12 . The further shift of the central wavelength up to highest concentration of $40,000 \mathrm{ppm}$ of $\mathrm{CO}_{2}$ was observed, Error! Reference source not found.Figure 12.

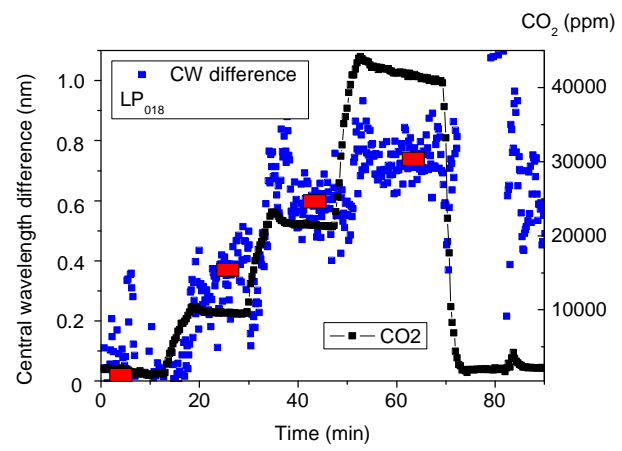

Figure 12: Array A (LPG1 coated with 40 layers of HKUST-1+bare LPG2) during the exposure to $\mathrm{CO}_{2}$ in the range from 500 ppm up to 40,000 ppm: dynamic change of the central wavelength difference corresponding to the LPo18 cladding mode of LPG1 (blueblack) and $\mathrm{CO}_{2}$ concentration (blackblue); red boxes indicates the intervals used for the calibration curve presented in Figure 13 Figure 13. 
The changes in $\triangle \mathrm{CW}_{\mathrm{LP018}}$ were monitored and the calibration curve was obtained, as shown in Figure

Formatted: English (United Kingdom) 13Figure 13. The use of the difference between the positions of the central wavelengths of the bare and coated LPG subtracts any environmental perturbations such as temperature or bending. The relatively high noise level expressed by error bars, calculated as the standard deviation at the stable conditions, are mostly due to small changes in the central wavelengths shift, close to the resolution of the spectrometer $(0.24 \mathrm{~nm})$.

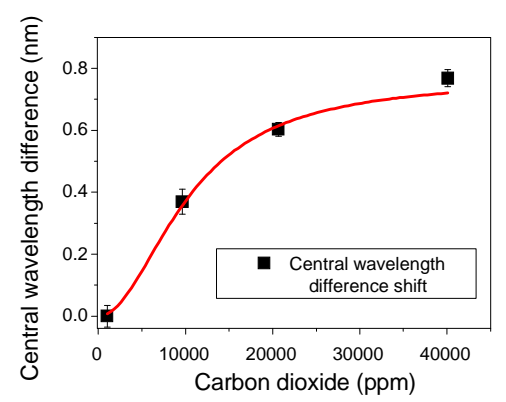

Figure 13: $\mathrm{CO}_{2}$ calibration curve (the error bars indicate the standard deviation over the stable conditions taken at each concentration step over the period of $3 \mathrm{~min}$ ).

The limit of detection (LOD) was calculated in relation to the average standard deviation of $0.04 \mathrm{~nm}$ obtained over the values measured in stable conditions (at 10,000 ppm concentration level) over the $3 \mathrm{~min}$ period and using the calibration curve $\left(10,000 \mathrm{ppm}\right.$ causes $0.37 \mathrm{~nm}$ shift of $\left.\Delta \mathrm{CW}_{\mathrm{LP0} 018}\right)$, Figure 13Figure 12 and following equation,

$$
L O D=\frac{S_{d}}{m}
$$

Where $S_{d}$ represent the standard deviation and $m$ indicates the linear slope for the interval up to 10,000 ppm (calculated as $3.74 \times 10^{-5}$ ). The LOD of $1070 \mathrm{ppm}$ was determined for the region up to $10,000 \mathrm{ppm}$.

The increase of the sensitivity could be achieved by increasing the thickness of the film however it was reported that film consisting of 80 layers lost the preferred $\{222\}$ crystal orientation enabling the optimal conditions of $\mathrm{CO}_{2}$ adsorption (49). Higher sensitivity can be obtained by optimising the LPG period to operate at the PMTP described in the next section. 


\subsection{Sensitivity improvements}

The results confirmed the feasibility of $\mathrm{CO}_{2}$ detection based upon LPGs coated with HKUST-1 thin films. In order to increase sensitivity and bring the sensor closer to real-world application, different LPGs, operating at the PMTP, were fabricated. HKUST-1 films consisting of 10, 20 and 40 layers were deposited on the surface of the single LPG with period of 108.8 (10 layers) and $109 \mu \mathrm{m}$ (20 and 40 layers). The changes in the transmission spectra in air before and after the deposition were monitored, Figure S8.

The sensors coated with 10, 20 and 40 layers of HKUST-1 were exposed to $\mathrm{CO}_{2}$ concentrations ranging from 1,450 to 41,200 ppm and the shift of the central wavelengths was noted, Table 1Table 1 .

Table 1: LPG sensor coated with 10, 20 and 40 layers of HKUST-1-CO sensitivity

\begin{tabular}{|c|c|c|c|c|c|}
\hline Sensor & $\begin{array}{c}\Delta \mathrm{CW} \mathrm{LP}_{019} \\
\approx 10 \mathrm{k} \mathrm{ppm} \\
\mathrm{CO}_{2}\end{array}$ & $\begin{array}{c}\Delta \mathrm{CW} \mathrm{LP}_{019} \\
\approx 20 \mathrm{k} \mathrm{ppm} \\
\mathrm{CO}_{2}\end{array}$ & $\begin{array}{c}\Delta \mathrm{CW} \mathrm{LP}_{019} \\
\approx 40 \mathrm{k} \mathrm{ppm} \\
\mathrm{CO}_{2}\end{array}$ & $\begin{array}{l}\text { Sensitivity (in } \\
\text { region up to } \\
10,000 \mathrm{ppm} \text { ) }\end{array}$ & $\Delta$ Temperature $(\mathrm{oC})$ \\
\hline 10 layers & $\begin{array}{l}0.97 \pm 0.17 \\
\mathrm{~nm}\end{array}$ & $\begin{array}{l}1.00 \pm 0.12 \\
\mathrm{~nm}\end{array}$ & $\begin{array}{l}0.95 \pm 0.15 \\
\mathrm{~nm}\end{array}$ & $\begin{array}{l}0.1 \pm 0.008 \mathrm{~nm} \\
/ 1,000 \mathrm{ppm}\end{array}$ & $0.92{ }^{\circ} \mathrm{C}$ \\
\hline 20 layers & $\begin{array}{l}4.45 \pm 0.17 \\
\mathrm{~nm}\end{array}$ & $\begin{array}{l}5.35 \pm 0.22 \\
\mathrm{~nm}\end{array}$ & $\begin{array}{l}5.47 \pm 0.23 \\
\mathrm{~nm}\end{array}$ & $\begin{array}{l}0.41 \pm 0.031 \\
\mathrm{~nm} / 1000 \mathrm{ppm}\end{array}$ & $0.93{ }^{\circ} \mathrm{C}$ \\
\hline 40 layers & $\begin{array}{l}7.2 \pm 0.25 \\
\mathrm{~nm}\end{array}$ & $\begin{array}{l}8.44 \pm 0.11 \\
\mathrm{~nm}\end{array}$ & $\begin{array}{l}10.58 \pm 0.12 \\
\mathrm{~nm}\end{array}$ & $\begin{array}{l}0.65 \pm 0.048 \\
\mathrm{~nm} / 1000 \mathrm{ppm}\end{array}$ & $0.37 ; 0.59 ; 0.85^{\circ} \mathrm{C}$ \\
\hline
\end{tabular}

The sensor coated with 10 layers showed the smallest response of $0.97 \pm 0.17 \mathrm{~nm}$ change in the central wavelength difference of the attenuation bands operating at the PMTP $\left(\Delta \mathrm{CW}_{\mathrm{LP019}}\right)$ when it was exposed to $10,000 \mathrm{ppm}$ of $\mathrm{CO}_{2}$. A small temperature increase was observed in the chamber after each injection of carbon dioxide. The temperature sensitivity measured as the change in the difference of the central wavelengths corresponding to $\mathrm{LP}_{019}$ cladding mode was calculated to be $\approx 0.92 \mathrm{~nm} /{ }^{\circ} \mathrm{C}$. When this temperature-induced change in $\mathrm{CW}$ is subtracted then $\Delta \mathrm{CW}_{\mathrm{LP} 019}$ of $0.12 \mathrm{~nm}$ was assumed to be caused by $\mathrm{CO}_{2}$ only. No further changes in the transmission spectrum were observed with increasing the $\mathrm{CO}_{2}$ concentration to $20,000 \mathrm{ppm}$.

A concentration of $\approx 10,000 \mathrm{ppm}$ of $\mathrm{CO}_{2}$ induced a change in the central wavelength difference of $4.45 \pm 0.17 \mathrm{~nm}$ for the sensor coated with 20 layers. The $\Delta \mathrm{CW}_{\mathrm{LP} 019}$ after the subtraction of the temperature effect was calculated to be $3.6 \mathrm{~nm}$ due to $\mathrm{CO}_{2}$. However minimal further shift of the central wavelengths was observed when $\mathrm{CO}_{2}$ concentration was increased up to $40,000 \mathrm{ppm}$ (after the subtraction of the temperature effect) 
The sensor coated with 40 layers showed the biggest response towards the exposure to $\mathrm{CO}_{2}$. The continuous shift of the central wavelength difference was observed over the whole concentration range up to $41,200 \mathrm{ppm}$, where it reached to $10.58 \pm 0.12 \mathrm{~nm}$ ( $9.8 \mathrm{~nm}$ after the temperature effect subtraction). The change in the transmission spectrum is shown in Figure 14Figure 14.

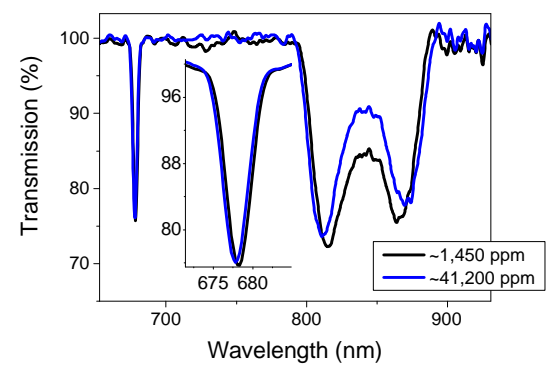

Figure 14: LPG sensor coated with 40 layers of HKUST-1: a) Transmission spectra at ambient indoor air concentration of 1,450 (black) and at exposed to 41,200 ppm of $\mathrm{CO}_{2}$ (blue); the inset shows the attenuation band corresponding to the LPors cladding mode in detail.

The changes in central wavelength difference of the attenuation bands operating at the PMTP were plotted as function of $\mathrm{CO}_{2}$ and the calibration curve was obtained, Figure 15Figure 15. It was mentioned that the position of the central wavelength was affected by temperature, with a slope of $0.92 \mathrm{~nm} /{ }^{\circ} \mathrm{C}$. The subtraction of this temperature effect from the change in the position of the central wavelengths was applied to the calibration curve, Figure 15Figure 15 (blue spots).

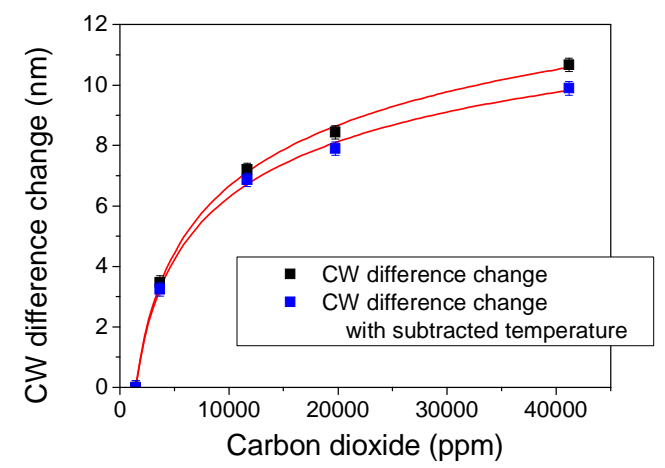

Formatted: Font: Not Italic

Formatted: Font: Not Italic

Formatted: Font: Not Italic 
Figure 15: LPG sensor coated with 40 layers of HKUST-1: $\mathrm{CO}_{2}$ calibration curve before (black) and after the temperature level was subtracted (blue).

The limit of detection (LOD) (the smallest detectable difference in $\mathrm{CO}_{2}$ concentration) was calculated in relation to the average standard deviation of $0.28 \mathrm{~nm}$ obtained over the values measured in stable conditions (at each concentration level) over the $3 \mathrm{~min}$ period and from the calibration curve (after the subtraction of temperature). The LOD of $401 \mathrm{ppm}$ was determined for the range of up to 10,000 ppm and the LPG based sensor coated with 40 layers of HKUST-1.

The response time of $110 \mathrm{~s}$ was obtained for the LPG based sensor coated with 40 layers of HKUST-1. The calculation was done according to the time when the sensor reached $90 \%$ of the signal response, expressed as the shift of the $\Delta \mathrm{CW}_{\mathrm{LP} 019}$, while exposed to $10,000 \mathrm{ppm}$ of $\mathrm{CO}_{2}$. The response time of $260 \mathrm{~s}$ was calculated for the commercial device using the same principle.

The sensor provides sufficient sensitivity for the detection of carbon dioxide for indoor air quality, where the target range of $\approx 400-10,000 \mathrm{ppm}$ is required (2). The practical use of the sensor in the real environment is compromised by the effect of the ambient relative humidity. The further work should target the development of a protective layer for separation of the water molecules. However, the sensor can still be used in the food industry, e.g. for monitoring of food packaging processes (3), where only the mixture of oxygen, nitrogen and carbon dioxide is used (11).

\section{Conclusions}

An HKUST-1 film was deposited successfully onto the surface of an optical fibre LPG using the in-situ crystallization and the layer-by layer technique and the response of the transmission spectra was characterized. The linear shift of the central wavelength during the deposition indicates the uniform growth of the HKUST-1 film with the increasing number of layers.

HKUST-1 thin film was characterized using SEM, XRD and ellipsometer. The X-ray diffraction pattern obtained with use of XRD matches well with the previously reported data and proved the deposition of HKUST- 1 film with desired $\{222\}$ orientation. The thickness of the film of $2 \mu \mathrm{m}$ and $55 \mathrm{~nm}$ was established for the film deposited with use of in-situ crystallization and layer by layer (40 layers) approach respectively. LbL technique enabled much better control over the thickness of the film.

The LPG coated by HKUST-1 via in-situ crystallization technique did not show chemical sensitivity to $\mathrm{CO}_{2}$. This could be explained as it greatly exceeds the optimum thickness of the sensing layer. The LPG 
coated with 40 layers HKUST-1 responded to $\mathrm{CO}_{2}$ concentrations in the range of $\approx 2,000-40,000 \mathrm{ppm}$ and the LOD of $401 \mathrm{ppm}$ was obtained. Thinner films showed a smaller response to $\mathrm{CO}_{2}$ concentrations up to $10,000 \mathrm{ppm}$ with further saturation of the sensor.

The obtained LOD in a range of $100 \mathrm{~s} \mathrm{ppm}$ of $\mathrm{CO}_{2}$ suggests the potential of the sensor for real world applications. The further improvement could be done by using a higher resolution spectrometer and combined approach of data analysis (including the transmission, central wavelength and width change).

The novel concept of the LPG based $\mathrm{CO}_{2}$ sensor coated with a MOF material has been demonstrated. The study on cross-sensitivity, deformation of the film by ambient $\mathrm{RH}$ and the implementation of the sensor into a multi-parameter sensing array can be included in the further work.

\section{Acknowledgments}

The authors would like to thank to Nigel Neate and Martin Roe for their help with XRD and SEM analysis.

\section{References}

1. Cox PM, Betts R a, Jones CD, Spall S a, Totterdell IJ. Acceleration of global warming due to carboncycle feedbacks in a coupled climate model. Nature. 2000;408(6809):184-7.

2. Crump D. Investigating indoor air quality problems: best practice and case studies. Proc ICE -

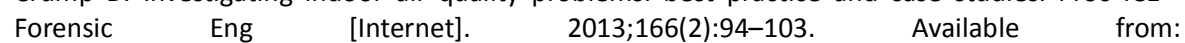
http://www.icevirtuallibrary.com/content/article/10.1680/feng.13.00001

3. Neethirajan S, Jayas DS, Sadistap S. Carbon dioxide ( $\mathrm{CO} 2$ ) sensors for the agri-food industry-A review. Food Bioprocess Technol. 2009;2(2):115-21.

4. 00006565-199308000-00017.pdf.

5. Liu X, Byrne RH, Adornato L, Yates KK, Kaltenbacher E, Ding X, et al. In situ spectrophotometric measurement of dissolved inorganic carbon in seawater. Environ Sci Technol. 2013;47(19):1110614.

6. Health and Safety Executive. EH4O / 2005 Workplace exposure limits EH4O / 2005 Workplace exposure limits. Eh40/2005. 2011;(March 2013):1-74.

7. Chatzidiakou L, Mumovic D, Summerfield AJ. What do we know about indoor air quality in school classrooms? A critical review of the literature. Intell Build Int. 2012;4(4).

8. Geelen LMJ, Huijbregts MAJ, Ragas AMJ, Bretveld RW, Jans HWA, Van Doorn WJ, et al. Comparing the effectiveness of interventions to improve ventilation behavior in primary schools. Indoor Air. 2008;18(5):416-24.

9. Hänninen $O$. Novel second-degree solution to single zone mass-balance equation improves the use of build-up data in estimating ventilation rates in classrooms. J Chem Heal Saf. 2013;20(2):14-9.

10. Chua KJ, Chou SK, Yang WM, Yan J. Achieving better energy-efficient air conditioning - A review of technologies and strategies. Appl Energy [Internet]. 2013;104:87-104. Available from: http://dx.doi.org/10.1016/j.apenergy.2012.10.037

11. Smolander M, Hurme E, Ahvenainen R. Leak indicators for modified-atmosphere packages. Trends 
Food Sci Technol. 1997;8(4):101-6.

12. Jayas DS, Irvine DA, Mazza G, Jeyamkondan S. Evaluation of a computer-controlled ventilation system for a potato storage facility. Can Biosyst Eng / Le Genie des Biosyst au Canada. 2001;43(Asae 1991):55-512.

13. Zhang SB, Zhai HC, Huang SX, Cai JP. A site-directed $\mathrm{CO} 2$ detection method for monitoring the spoilage of stored grains by insects and fungi in Chinese horizontal warehouses. J Stored Prod Res [Internet]. 2014;59(October 2014):146-51. Available from: http://dx.doi.org/10.1016/j.jspr.2014.07.002

14. Hunter CL, Silvestri S, Dean M, Falk JL, Papa L. End-tidal carbon dioxide is associated with mortality and lactate in patients with suspected sepsis. Am J Emerg Med [Internet]. 2013;31(1):64-71. Available from: http://dx.doi.org/10.1016/j.ajem.2012.05.034

15. BAUDENDISTEL L, GOUDSOUZIAN N, COTE C, STRAFFORD M. End-tidal CO2 monitoring. Anaesthesia [Internet]. 1984;39(10):1000-3. Available from: http://dx.doi.org/10.1111/j.13652044.1984.tb08889.x

16. Kersey AD. A Review of Recent Developments in Fiber Optic Sensor Technology. Opt Fiber Technol [Internet]. 1996;2:291-317. Available from: http://www.sciencedirect.com/science/article/pii/S106852009690036X

17. Rego G. A review of refractometric sensors based on long period fibre gratings. Sci World J. 2013;2013.

18. James SW, Tatam RP. Optical fibre long-period grating sensors: characteristics and application. Meas Sci Technol. 2003;14(5):R49-61.

19. Patrick HJ, Kersey AD, Bucholtz F. Analysis of the response of long period fiber gratings to external index of refraction. J Light Technol. 1998;16(9):1606-12.

20. Korposh S, Selyanchyn R, Yasukochi W, Lee SW, James SW, Tatam RP. Optical fibre long period grating with a nanoporous coating formed from silica nanoparticles for ammonia sensing in water. Mater Chem Phys [Internet]. 2012;133(2-3):784-92. Available from: http://dx.doi.org/10.1016/j.matchemphys.2012.01.094

21. Cusano A, Pilla P, Contessa L, Iadicicco A, Campopiano S, Cutolo A, et al. High-sensitivity optical chemosensor based on coated long-period gratings for sub-ppm chemical detection in water. Appl Phys Lett. 2005;87(23):1-3.

22. Venugopalan T, Sun T, Grattan KTV. Long period grating-based humidity sensor for potential structural health monitoring. Sensors Actuators, A Phys. 2008;148(1).

23. Ishaq IM, Quintela A, James SW, Ashwell GJ, Lopez-Higuera JM, Tatam RP. Modification of the refractive index response of long period gratings using thin film overlays. Sensors Actuators, B Chem. 2005;107(2):738-41.

24. Urrutia A, Goicoechea J, Ricchiuti AL, Barrera D, Sales S, Arregui FJ. Simultaneous measurement of humidity and temperature based on a partially coated optical fiber long period grating. Sensors Actuators, B Chem [Internet]. 2016;227:135-41. Available from: http://dx.doi.org/10.1016/j.snb.2015.12.031

25. Alwis L, Sun T, Grattan KTV. Fibre optic long period grating-based humidity sensor probe using a Michelson interferometric arrangement. Sensors Actuators B Chem [Internet]. 2013 Mar [cited 2016 May 21];178:694-9. Available from: http://www.sciencedirect.com/science/article/pii/S0925400512012580

26. Wang T, Korposh S, Wong R, James S, Tatam R, Lee S-W. A Novel Ammonia Gas Sensor Using a Nanoassembled Polyelectrolyte Thin Film on Fiber-optic Long-period Gratings. Chem Lett [Internet]. 2012;41(10):1297-9. Available from: http://www.scopus.com/inward/record.url?eid=2-s2.084868268827\&partnerID=tZOtx3y1

27. Topliss SM, James SW, Davis F, Higson SPJ, Tatam RP. Optical fibre long period grating based selective vapour sensing of volatile organic compounds. Sensors Actuators, B Chem. 2010;143(2):629-34. 
28. Hromadka J, Tokay B, James S, Tatam RP, Korposh S. Optical fibre long period grating gas sensor modified with metal organic framework thin films. Sensors Actuators, B Chem. 2015;221:891-9.

29. Arregui FJ, Matias IR, Corres JM, Del Villar I, Goicoechea J, Zamarreño CR, et al. Optical fiber sensors based on Layer-by-Layer nanostructured films. Procedia Eng [Internet]. 2010;5:1087-90. Available from: http://www.scopus.com/inward/record.url?eid=2-s2.0-78650589671\&partnerlD=tZOtx3y1

30. Marques L, Hernandez FU, James SW, Morgan SP, Clark M, Tatam RP, et al. Highly sensitive optical fibre long period grating biosensor anchored with silica core gold shell nanoparticles. Biosens Bioelectron [Internet]. 2016;75:222-31. Available from: http://dx.doi.org/10.1016/j.bios.2015.08.046

31. Sozzi M, Cucinotta A, Corradini R, Marchelli R, Konstantaki M, Pissadakis S, et al. Label-free DNA detection with PNA modified long period fiber grating-based sensor. In: Optics InfoBase Conference Papers. 2011.

32. Pilla P, Sandomenico A, Malachovská V, Borriello A, Giordano M, Cutolo A, et al. A protein-based biointerfacing route toward label-free immunoassays with long period gratings in transition mode. Biosens Bioelectron [Internet]. 2012;31(1):486-91. Available from: http://dx.doi.org/10.1016/j.bios.2011.11.022

33. Ariga K, Yamauchi Y, Rydzek G, Ji Q, Yonamine Y, Wu KC-W, et al. Layer-by-layer Nanoarchitectonics: Invention, Innovation, and Evolution. Chem Lett [Internet]. 2014;43(1):36-68. Available from: http://jlc.jst.go.jp/DN/JST.JSTAGE/cl/130987?lang=en\&from=CrossRef\&type=abstract

34. Hromadka J, Korposh S, Partridge MC, James SW, Davis F, Crump D, et al. Multi-parameter measurements using optical fibre long period gratings for indoor air quality monitoring. Sensors Actuators, B Chem. 2017;244.

35. Yaghi OM, O'Keeffe M, Ockwig NW, Chae HK, Eddaoudi M, Kim J. Reticular synthesis and the design of new materials. Nature. 2003;423(6941):705-14.

36. Kreno LE, Leong K, Farha OK, Allendorf M, Duyne RP Van, Hupp JT. Metal À Organic Framework Materials as Chemical Sensors. Chem Rev. 2012;112:1105-25.

37. Furukawa H, Cordova KE, O'Keeffe M, Yaghi OM. The chemistry and applications of metal-organic frameworks. Science [Internet]. 2013;341(6149):1230444. Available from: http://www.sciencemag.org/content/341/6149/1230444.full

38. Kuppler RJ, Timmons DJ, Fang Q-R, Li J-R, Makal TA, Young MD, et al. Potential applications of metalorganic frameworks. Coord Chem Rev [Internet]. 2009 Dec [cited 2016 Apr 20];253(23-24):304266. Available from: http://www.sciencedirect.com/science/article/pii/S0010854509001271

39. Mueller U, Schubert M, Teich F, Puetter H, Schierle-Arndt K, Pastré J. Metal-organic frameworksprospective industrial applications. J Mater Chem [Internet]. 2006;16(7):626-36. Available from: http://pubs.rsc.org/en/content/articlehtml/2006/jm/b511962f

40. Suh MP, Park HJ, Prasad TK, Lim D. Hydrogen Storage in Metal À Organic Frameworks. 2012;782835.

41. Li J-R, Kuppler RJ, Zhou H-C. Selective gas adsorption and separation in metal-organic frameworks. Chem Soc Rev [Internet]. 2009 May [cited 2016 May 26];38(5):1477-504. Available from: http://www.scopus.com/inward/record.url?eid=2-s2.0-65349158272\&partnerlD=tZOtx3y1

42. Yoon $M$, Srirambalaji R, Kim K. Homochiral metal-organic frameworks for asymmetric heterogeneous catalysis. Chem Rev. 2012;112(2):1196-231.

43. Betard A and, Fischer RA. Metal À Organic Framework Thin Films: From Fundamentals to. 2012;1055-83.

44. Lu G, Hupp JT. Metal Organic Franeworks as Sensors A ZIF ( Based Fabry Perot Device as a Selective Sensor for Chemical Vapours and Gases.pdf. 2010;7832-3.

45. Gutierrez-Sevillano, Juan Jose Vicent-Luna JM, Dubbeldam D, Calero S. Molecular mechanisms for adsorption in Cu-BTC metal organic framework. J Phys Chem C. 2013;117(21):11357-66.

46. Greeves N. No Title. chemtube3D.com. 
47. Shah MN, Gonzalez M a, McCarthy MC, Jeong H-K. An unconventional rapid synthesis of high performance metal-organic framework membranes. Langmuir [Internet]. 2013;29(25):7896-902. Available from: http://www.ncbi.nlm.nih.gov/pubmed/23721152

48. So MC, Jin S, Son H, Wiederrecht GP, Farha OK, Hupp JT. Layer-by-Layer Fabrication of Oriented Porous Thin Films Based on Porphyrin-Containing Metal - Organic Frameworks. 2013;(L):1-4.

49. Nijem N, F??rsich K, Kelly ST, Swain C, Leone SR, Gilles MK. HKUST-1 thin film layer-by-layer liquid phase epitaxial growth: film properties and stability dependence on layer number. Cryst Growth Des. 2015;15(6):2948-57.

50. Wong RYN, Chehura E, Staines SE, James SW, Tatam RP. Fabrication of fiber optic long period gratings operating at the phase matching turning point using an ultraviolet laser. Appl Opt [Internet]. 2014;53(21):4669-74. Available from: http://www.ncbi.nlm.nih.gov/pubmed/25090202

51. Hromadka J, Correia R, Korposh S. Fabrication of fiber optic long period gratings operating at the phase matching turning point using an amplitude mask. In: Proceedings of SPIE - The International Society for Optical Engineering. 2016.

52. Korposh S, Lee S-W, James SW, Tatam RP. Refractive index sensitivity of fibre optic long period gratings with SiO2 nanoparticle based mesoporous coatings. 2011;7753:19-22. Available from: http://dx.doi.org/10.1117/12.884777

53. Waich K, Mayr T, Klimant I. Microsensors for detection of ammonia at ppb-concentration levels. Meas Sci Technol [Internet]. 2007;18(10):3195-201. Available from: http://www.iop.org/EJ/abstract/0957-0233/18/10/S22/

54. Tao $S, X u L$, Fanguy JC. Optical fiber ammonia sensing probes using reagent immobilized porous silica coating as transducers. Sensors Actuators, B Chem. 2006;115(1):158-63. 